\title{
p15 promoter methylation - A novel prognostic marker in glioblastoma patients
}

\author{
SILKE WEMMERT ${ }^{1}$, MARC BETTSCHEIDER ${ }^{1}$, SIMONE ALT $^{1}$, RALF KETTER ${ }^{1}$, \\ KAI KAMMERS ${ }^{2}$, WOLFGANG FEIDEN ${ }^{3}$, WOLF-INGO STEUDEL ${ }^{1}$, \\ JÖRG RAHNENFÜHRER ${ }^{2}$ and STEFFI URBSCHAT ${ }^{1}$ \\ ${ }^{1}$ Department of Neurosurgery, Saarland University, Building 90.5, D-66421 Homburg/Saar; \\ ${ }^{2}$ Department of Statistics, Dortmund University of Technology, D-44221 Dortmund; \\ ${ }^{3}$ Institute of Neuropathology, Saarland University, Building 90.3, D-66421 Homburg/Saar, Germany
}

Received December 8, 2008; Accepted January 30, 2009

DOI: 10.3892/ijo_00000305

\begin{abstract}
Glioblastomas are the most frequent and malignant brain tumors in adults. Surgical cure is virtually impossible and despite radiation and chemotherapy the clinical course is very poor. Epigenetic silencing of $M G M T$ has been associated with a better response to temozolomide-chemotherapy. We previously showed that temozolomide increases the median survival time of patients with tumors harbouring deletions on $9 \mathrm{p}$ within the region for $p 15$ (INK4b), p16(INK4a), and $10 \mathrm{q}(M G M T)$. The aim of this study was to investigate the methylation status of $p 15, p 16, p 14^{A R F}$ and MGMT in glioblastomas $(\mathrm{n}=27)$ and to correlate the results with the clinical data. Only patients with KPS $>70$, radical tumor resection, radiation and temozolomide-chemotherapy after recurrence were included. We observed promoter methylation of MGMT in 56\% and of p15 in $37 \%$ of the tumors, whereas methylation of p16 and $p 14^{A R F}$ were rare. Interestingly, methylation of $p 15$ emerged as a significant predictor of shorter overall survival (16.9 vs. 23.8 months, $\mathrm{p}=0.025$ ), whereas $M G M T$ promoter methylation had no significant effect on median overall survival under this treatment regimen ( 22.5 vs. 22.1 months, $\mathrm{p}=0.49$ ). In the presence of other clinically relevant factors, $p 15$ methylation remains the only significant predictor $(\mathrm{p}=0.021)$. Although these results need to be confirmed in larger series as well as under different treatment conditions, our retrospective study shows clear evidence that $p 15$ methylation is an important prognostic factor for survival and underlines that this tumor suppressor, involved in cell cycle control, is an attractive candidate for therapeutic approaches in glioblastomas.
\end{abstract}

Correspondence to: Dr Steffi Urbschat, Department of Neurosurgery, Saarland University, Building 90.5, D-66421 Homburg, Germany

E-mail: hgsmur@uks.eu

Key words: glioblastoma, methylation, prognosis, p15, MGMT

\section{Introduction}

Glioblastomas [World Health Organization (WHO) grade IV] are the most frequent and the most malignant brain tumors in adults. They arise either de novo without recognizable precursor lesions or develop from lower grade astrocytomas (secondary GBM). Despite of multimodal therapy approaches, the prognosis is generally poor but varies markedly between the malignancy grades and even between individuals with the same malignancy grade. Less than half of the patients survive more than a year (1). Besides radical surgery, a higher preoperative Karnofsky Performance Score (KPS) and younger age are predictors of a more favorable clinical course (2-5).

Over the past decades, genetic abnormalities involved in pathogenesis and progression of these tumors were identified. Several alterations were also shown to be correlated with prognosis.

Deletion or mutation of the $p 16(I N K 4 a) / A R F / p 15(I N K 4 b)$ locus on chromosome $9 \mathrm{p} 21$ is among the most common alterations seen in human cancer and in human gliomas (6-9). The INK4a locus encodes two gene products that are involved in cell cycle regulation through inhibition of CDK4-mediated RB phosphorylation ( $p 16)$ and binding to MDM2 leading to p53 stabilization $\left(p 14^{A R F}\right)$. The tumor suppressor gene products p16 and p15 are both capable of binding to CDK4 and CDK6, these kinases associate with D-type cyclines and these binary complexes are responsible for phosphorylation of RB-protein at mid-G1 of the cell cycle. The phosphorylation of $\mathrm{RB}$ is assumed to be critical for progression through $\mathrm{G} 1$ and entry into S-phase of the cell cycle. Binding of INK4 to CDK4/6 inhibits its kinase activity and thereby arrests progression through the cell cycle in mid-late G1 (10).

Over half of the high grade gliomas lack a functional $I N K 4 a / A R F$ locus. Gliomas with intact INK4a/ARF carry mutations in other components of the RB and p53 pathways implicating these two pathways as being absolutely critical in cell growth and death control (11-14). Previous studies showed that deletion of $9 \mathrm{p}$ including the INK $4 a / b$ locus is a significant unfavorable prognostic factor for survival of glioblastoma patients $(15,16)$. Further on, this alteration has 
Table I. Patient characteristics and methylation status of MGMT, p15, p16 and p14 ${ }^{\mathrm{ARF}}$.

\begin{tabular}{|c|c|c|c|c|c|c|c|}
\hline Case & Histologic type & Age/sex & ST (months) & MGMT-status & p15-status & p16-status & p14 ${ }^{\mathrm{ARF}}$-status \\
\hline T4789 & GBM & $38 / \mathrm{m}$ & 55.3 & M & $\mathrm{U}$ & $\mathrm{U}$ & $\mathrm{U}$ \\
\hline $596 / 98$ & GBM & $32 / \mathrm{m}$ & 21.1 & $\mathrm{U}$ & $\mathrm{U}$ & $\mathrm{U}$ & $\mathrm{U}$ \\
\hline $1099 / 98$ & GBM & $49 / \mathrm{m}$ & 23.8 & $\mathrm{U}$ & $\mathrm{U}$ & $\mathrm{U}$ & $\mathrm{U}$ \\
\hline $1782 / 98$ & sGBM & $26 / \mathrm{m}$ & 24,2 & M & $\mathrm{U}$ & $\mathrm{U}$ & $\mathrm{U}$ \\
\hline $896 / 99$ & GBM & $51 / \mathrm{m}$ & 13 & $\mathrm{U}$ & M & $\mathrm{U}$ & $\mathrm{U}$ \\
\hline $1326 / 99$ & GBM & $56 / \mathrm{m}$ & 19.2 & $\mathrm{U}$ & $\mathrm{U}$ & $\mathrm{U}$ & $\mathrm{U}$ \\
\hline $1349 / 99$ & GBM & $54 / \mathrm{m}$ & 72.6 & M & $\mathrm{U}$ & $\mathrm{U}$ & $\mathrm{U}$ \\
\hline $1460 / 99$ & GBM & $31 / f$ & 11.9 & M & M & $\mathrm{U}$ & $\mathrm{U}$ \\
\hline $1795 / 99$ & sGBM & $31 / \mathrm{m}$ & 6.9 & M & $\mathrm{U}$ & $\mathrm{U}$ & $\mathrm{U}$ \\
\hline $265 / 00$ & GBM & $46 / f$ & 23.1 & $\mathrm{U}$ & M & n.a. & $\mathrm{U}$ \\
\hline $497 / 00$ & GBM & $58 / \mathrm{f}$ & 16.9 & M & M & $\mathrm{U}$ & $\mathrm{U}$ \\
\hline $1106 / 00$ & GBM & $70 / \mathrm{m}$ & 19.8 & M & M & $\mathrm{U}$ & $\mathrm{U}$ \\
\hline $1691 / 00$ & sGBM & $39 / f$ & 80.2 & M & $\mathrm{U}$ & $\mathrm{U}$ & $\mathrm{U}$ \\
\hline $1707 / 00$ & GBM & $47 / \mathrm{m}$ & 29.4 & $\mathrm{U}$ & $\mathrm{U}$ & $\mathrm{U}$ & $\mathrm{U}$ \\
\hline $643 / 01$ & GBM & $54 / f$ & 26.6 & $\mathrm{U}$ & $\mathrm{U}$ & $\mathrm{U}$ & $\mathrm{U}$ \\
\hline $662 / 01$ & GBM & $70 / \mathrm{m}$ & 13.4 & $\mathrm{U}$ & M & $\mathrm{U}$ & $\mathrm{U}$ \\
\hline $1405 / 01$ & GBM & $53 / \mathrm{m}$ & 7.4 & $\mathrm{U}$ & M & $\mathrm{M}$ & $\mathrm{U}$ \\
\hline $6 / 02$ & GBM & $41 / \mathrm{m}$ & 26.2 & M & $\mathrm{U}$ & $\mathrm{U}$ & $\mathrm{U}$ \\
\hline $369 / 02$ & sGBM & $37 / \mathrm{m}$ & 20.2 & M & $\mathrm{U}$ & $\mathrm{U}$ & $\mathrm{U}$ \\
\hline $947 / 02$ & GBM & $46 / \mathrm{m}$ & 17.7 & M & M & $\mathrm{U}$ & $\mathrm{U}$ \\
\hline $1536 / 02$ & GBM & $53 / \mathrm{m}$ & 15.1 & $\mathrm{U}$ & $\mathrm{U}$ & $\mathrm{U}$ & $\mathrm{U}$ \\
\hline $1940 / 02$ & GBM & $54 / f$ & 14.3 & M & M & $\mathrm{U}$ & $\mathrm{U}$ \\
\hline XXL/02 & GBM & $45 / \mathrm{m}$ & 8.6 & M & $\mathrm{U}$ & $\mathrm{U}$ & $\mathrm{U}$ \\
\hline $316 / 03$ & GBM & $63 / f$ & 23.7 & $\mathrm{U}$ & $\mathrm{U}$ & n.a. & $\mathrm{U}$ \\
\hline $784 / 03$ & GBM & $52 / \mathrm{m}$ & 22.5 & M & $\mathrm{U}$ & $\mathrm{U}$ & $\mathrm{U}$ \\
\hline $831 / 03$ & GBM & $58 / \mathrm{m}$ & 53 & $\mathrm{U}$ & $\mathrm{U}$ & n.a. & $\mathrm{U}$ \\
\hline $1457 / 03$ & GBM & $37 / \mathrm{m}$ & 49.1 & M & M & n.a. & $\mathrm{U}$ \\
\hline
\end{tabular}

GBM, glioblastoma multiforme; sGBM, secondary glioblastoma multiforme; m, male; f, female; ST, survival time; M, methylated; U, unmethylated; n.a., not available.

been reported to be inversely correlated with the chemosensitivity of malignant gliomas (17).

Over recent years aberrant DNA methylation was shown to be a common molecular lesion in human tumors as well, which had also impact on patient prognosis and treatment response. Epigenetic silencing of p16 and p15 was shown in a variety of human neoplasms, in glioma patients hypermethylation is reported in about 30\% of the cases (18-21). Whereas in other tumors inactivation of both tumor suppressor genes was associated with prognosis and response to chemotherapy, a prognostic and predictive role in gliomas is not shown $(9,22-24)$.

On the other hand, epigenetic silencing of the DNA repair gene $O^{6}$-methylguanine-DNA methyltransferase (MGMT) on chromosome $10 \mathrm{q} 26$ by hypermethylation has been linked to a better prognosis for glioblastoma patients treated with alkylating agents like temozolomide (25-28), whereas no benefit was observed for patients with MGMT promoter methylation and BCNU-chemotherapy (29). Another study comparing different treatment regimens showed that the prognostic effect was only significant when patients were treated simultaneously with radio- and temozolomide-chemotherapy (30). These results suggest that the reported impact of MGMT methylation is strongly dependent on therapeutic modalities and schedules.

In our previous study we identified a negative prognostic impact for deletions on $9 \mathrm{p}$ and $10 \mathrm{q}$, which can be compensated by temozolomide treatment (16). In the current setting, we investigated the methylation status of $p 15, p 16, p 14^{A R F}$ and $M G M T$, and correlated the results with the clinical data of the glioblastoma patients.

\section{Patients and methods}

Patients and tumor samples. The retrospective study included 27 glioblastoma patients (23 primary and 4 secondary GBM) 
A
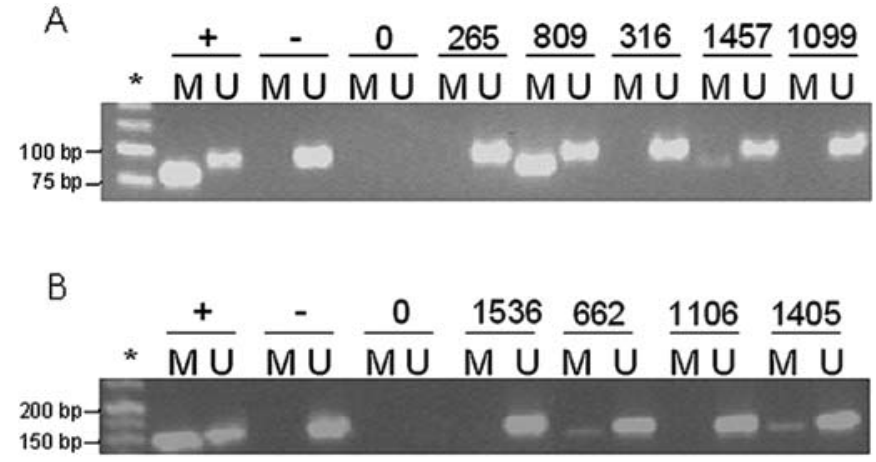

Figure 1. Methylation specific PCR of: (A) MGMT; and (B) p15 promotor in GBMs. *, Molecular size marker; U, unmethylated DNA; M, methylated DNA; +, positive control; -, negative control; 0 , blank value.

who underwent surgery at the Department of Neurosurgery of the Saarland University, Homburg, Germany. After radical tumor surgery, all patients received standard radiation therapy (RT) (1.8-2 Gy, total dose of $60 \mathrm{~Gy}$ ) and adjuvant temozolomide chemotherapy in case of recurrence. The doses were $150 \mathrm{mg} / \mathrm{m}^{2}$ for 5 days in 4 week cycles. Specimens of resected tumor were immediately shock-frozen in liquid nitrogen and stored at $-80^{\circ} \mathrm{C}$ or fixed in formalin and embedded in paraffin for histopathological diagnosis. The patients gave written informed consent for the use of the tumor samples for genetic analysis.

Methylation-specific polymerase chain reaction (MS-PCR). DNA from fresh frozen tumor samples was isolated following standard protocols with chloroform followed by sodium bisulfite modification. Promoter hypermethylation of the $M G M T, p 15, p 16$ and $p 14^{A R F}$ genes were determined by MS-PCR as described previously $(18,25,31)$. The amplified products were electrophoresed on $3.5 \%$ agarose gels and visualized with ethidium bromide. Methylated blood DNA was included in each PCR set as methylated and unmethylated controls, respectively.

Statistical analyses. Comparison of survival times between groups defined by methylation status was performed by Kaplan-Meier curves and with two-sided log-rank tests. Multivariate Cox regression analysis was performed to identify significant predictors for survival. Effects in these models were quantified by hazard ratio estimates with $95 \%$ confidence intervals. Median survival rates were calculated using the Kaplan-Meier method.

\section{Results}

Clinical data. Median age at surgery was 49 years (range 26-70), the sex ratio was 2.375 ( $19 \mathrm{men} / 8$ women) (Table I) and median post-operative KPS was 100 (range 80-100, 18 patients with KPS 100).

Methylation analysis. The MGMT promoter was methylated in $15 / 27$ cases $(55.6 \%)$, the $p 15$ promoter was methylated in 10/27 (37\%) glioblastomas (Fig. 1). All secondary GBM (4/4) showed a methylated $M G M T$ promoter and an unmethylated

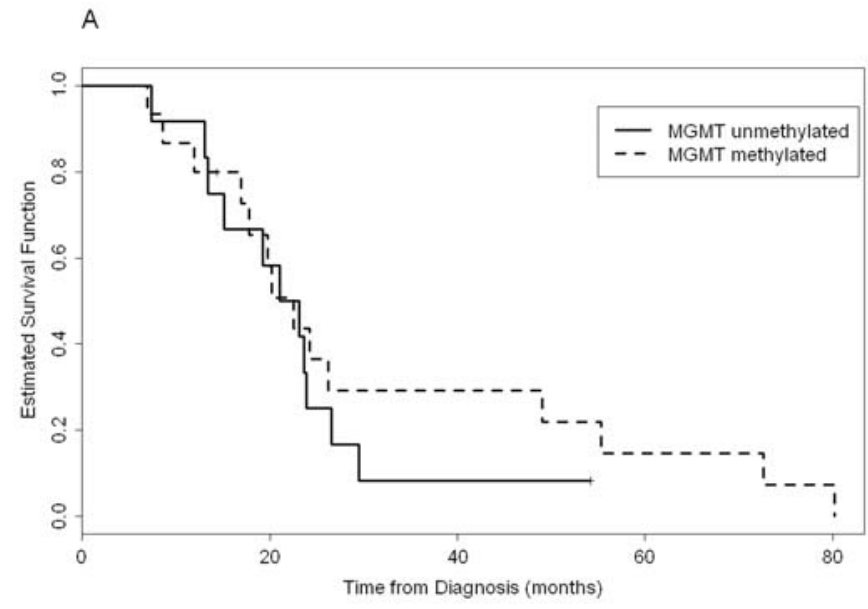

B

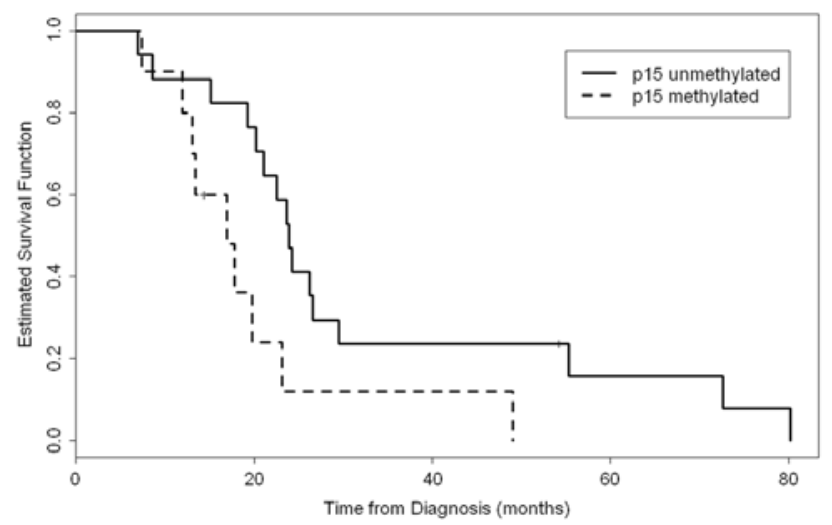

Figure 2. Kaplan-Meier survival curves. Overall survival of: (A) MGMT methylation; and (B) p15 methylation. Censored data (patients still alive) are plotted as hash marks.

p15 promoter. Methylation of $p 14^{A R F}$ was absent in all (27/27) investigated GBM. Methylation status of $p 16$ was available for 23/27 glioblastomas. Hypermethylation of $p 16$ was detected in only $1 / 23$ cases $(4.3 \%$ ) (Table I).

Clinical outcome. Overall median survival was 22.5 months with a 2-year survival rate of $35.0 \%$. One patient $(831 / 03)$ was alive at end of follow-up with a survival time of 53 months and one patient (case 1940/02) was lost of follow-up.

In univariate analyses, $M G M T$ methylation had no impact on overall survival ( 22.5 vs. 22.1 months, $\mathrm{p}=0.49$, log-rank test, Fig. 2A), whereas p15 methylation was associated significantly with a shorter overall survival ( 16.9 vs. 23.8 months; $\mathrm{p}=0.0252$, log-rank test, Fig. 2B). Table IIA contains estimated hazard ratios and p-values for univariate analyses for all examined variables.

We also performed a multivariate analysis including all parameters used in the univariate models. As shown in Table IIB, only p15 methylation emerged as a significant prognostic factor after adjusting for KPS, sex, age and MGMT. In the first analysis, the predictors KPS and age enter as numerical variables in the model, in the second analysis KPS and age are dichotomized with cut-offs 90 and 50 in order to reduce model complexity. The gender variable sex is set 
Table II. Overall survival in glioblastoma patients.

\begin{tabular}{|c|c|c|c|c|}
\hline Variable & Hazard ratio & $95 \% \mathrm{CI}$ & $\mathrm{SD}$ & p-value \\
\hline \multicolumn{5}{|c|}{ A, Univariate Cox-regression analysis } \\
\hline KPS & 1.089 & $0.983-1.21$ & 0.052 & 0.095 \\
\hline $\mathrm{KPS} \geq 90$ & 0.214 & $0.025-1.83$ & 1.100 & 0.121 \\
\hline Sex & 0.826 & $0.325-2.10$ & 0.476 & 0.687 \\
\hline Age & 1.014 & $0.973-1.06$ & 0.021 & 0.508 \\
\hline Age $\leq 50$ & 0.813 & $0.362-1.83$ & 0.414 & 0.617 \\
\hline MGMT methylation & 0.744 & $0.320-1.73$ & 0.431 & 0.490 \\
\hline p15 methylation & 2.655 & $1.100-6.42$ & 0.451 & 0.025 \\
\hline \multicolumn{5}{|c|}{$\mathrm{B}$, Multivariate Cox-regression analysis } \\
\hline KPS & 1.067 & $0.963-1.18$ & 0.0521 & 0.210 \\
\hline Sex & 0.636 & $0.238-1.70$ & 0.5018 & 0.370 \\
\hline Age & 1.015 & $0.972-1.06$ & 0.0222 & 0.500 \\
\hline MGMT methylation & 0.638 & $0.240-1.70$ & 0.4982 & 0.370 \\
\hline p15 methylation & 2.705 & $1.010-7.25$ & 0.5027 & 0.048 \\
\hline \multicolumn{5}{|c|}{$\begin{array}{l}\text { Multivariate Cox-regression analysis } \\
\text { with dichotomous variables }\end{array}$} \\
\hline KPS $\geq 90$ & 0.668 & $0.0635-7.02$ & 1.201 & 0.740 \\
\hline Sex & 0.682 & $0.2544-1.83$ & 0.503 & 0.450 \\
\hline Age $\leq 50$ & 0.810 & $0.3371-1.95$ & 0.447 & 0.640 \\
\hline MGMT methylation & 0.615 & $0.2388-1.59$ & 0.483 & 0.310 \\
\hline p15 methylation & 3.198 & $1.1871-8.62$ & 0.506 & 0.021 \\
\hline
\end{tabular}

KPS, Karnofsky Performance Score; CI, confidence interval; SD, standard deviation.

to 1 for females and 0 for males. Both analyses yield very similar results, identifying p15 methylation as the only significant predictor.

\section{Discussion}

A better understanding of the genetic alterations predicting disease outcome and therapy response in patients with high grade gliomas will help to optimize both treatment and overall outcome. Our study confirms the fact that the prognostic significance of $M G M T$ promoter methylation depends strongly on the treatment regimen. Actually, comparing various treatment modalities in glioblastomas, the prognostic effect of MGMT methylation was observed only when simultaneous chemoirradiation was administered and not when temozolomide was administered adjuvant after tumor recurrence as in our study setting $(25,27,30,32)$.

Further on, our PCR-results showed besides the methylated band also unmethylated bands in a large number of tumors (Fig. 1). Taking into account the heterogeneity of these diffusely and infiltrating growing gliomas $(33,34)$, this observation arises most likely from a different tumor cell population and from normal cells contaminating the tumor sample. Nevertheless, this heterogeneous methylation pattern may also result in different amounts of MGMT and therefore affect chemotherapy response which would be interesting to investigate in a larger patient cohort.

All evidence collected to date implicates that the INK4a/ ARF gene products are critically important in control of growth arrest and senescence. Loss of p16 and ARF expression is associated with many human cancers, particularly gliomas (20). A number of studies have shown that reconstitution of INK4a/ARF expression in glioma cells altered growth characteristics, reduced tumorigenicity and decreased invasive potential. These studies demonstrate the importance of the $I N K 4 a / A R F$ pathway in suppression of the neoplastic phenotype and suggest that restoration of a functional INK $4 a / A R F$ locus will be an important means of controlling the growth of gliomas $(35,36)$.

The striking observation of our study is the significant correlation of $p 15$ methylation with a poorer clinical course. Loss of $p 15$ has not been widely investigated previously as a potential determinant of chemo- and radiosensitivity or as a prognostic factor. To our knowledge, this is the first study showing inactivation of $p 15$ by promoter hypermethylation to be a predictor for an unfavorable clinical course. Cyclindependent kinase inhibitors (p16, p21, p27) were shown to exhibit an antitumor effect in malignant gliomas inducing 
growth arrest and apoptosis in cell culture $(35,36)$. Moreover, retrovirus-mediated transfer of INK4a halts glioma formation in a rat model (37). This corroborates the idea that retrovirusmediated gene transfer of INK4a/b may also be an effective means to arrest human gliomas. Therefore, restoring the normal function of $\mathrm{p} 15$ by gene therapy might be an attractive goal in the treatment of human gliomas.

Furthermore, a general defect in their pattern of $\mathrm{CpG}$ island methylation can be excluded because the investigated glioblastomas have not simultaneously hypermethylated the investigated tumor suppressor genes on 9p. Interestingly, all secondary GBM (4/4) showed a methylated MGMT promoter and an unmethylated $p 15$ promoter which underlines that distinct molecular pathways constitute the primary and the secondary glioblastomas and are responsible for their different biological behavior and in clinical outcome. This corresponds to the finding that methylation of $M G M T$ promoter is mutually exclusive of $p 14^{A R F}$ methylation and the latter is associated with a shorter patient survival, except in one case of low grade astrocytoma who underwent progression or recurrence (38).

In our patient cohort, $p 14^{A R F}$ methylation was not observed. Hence our cohort mainly consists of primary glioblastomas, a larger sample size of secondary glioblastomas has to be analyzed to clarify if this alteration is mainly restricted to secondary glioblastoma and therefore is an important step in the pathway of astrocytoma progression.

Although these results need to be confirmed in larger series, our retrospective study suggests that $p 15$ hypermethylation can act as an additional important prognostic factor for survival in glioblastomas. Further investigations have to clarify if $p 15$ methylation is a predictive factor for temozolomide treatment response and can act as a reliable prognostic parameter for survival, independent of therapy.

\section{Acknowledgments}

S. Urbschat and W.I. Steudel are recipients of a commercial research grant from Schering Plough, no. XX3528.

\section{References}

1. Louis DN, Ohgaki H, Wiestler OD and Cavenee WK: WHO Classification of Tumours of the Central Nervous System. 4th edition. International Agency for Research on Cancer, Lyon, 2007.

2. Burger PC and Green SB: Patient age, histologic features, and length of survival in patients with glioblastoma multiforme. Cancer 59: 1617-1625, 1987.

3. Kreth FW, Warnke PC, Scheremet R and Ostertag CB: Surgical resection and radiation therapy versus biopsy and radiation therapy in the treatment of glioblastoma multiforme. J Neurosurg 78: 762-766, 1993

4. Lacroix M, Abi-Said D, Fourney DR, et al: A multivariate analysis of 416 patients with glioblastoma multiforme: prognosis, extent of resection, and survival. J Neurosurg 95: 190-198, 2001.

5. Stummer W, Reulen HJ, Meinel T, et al: Extent of resection and survival in glioblastoma multiforme: Identification of and adjustment for bias. Neurosurgery 62: 564-576, 2008

6. Jen J, Harper JW, Bigner SH, et al: Deletion of p16 and p15 genes in brain tumors. Cancer Res 54: 6353-6358, 1994.

7. Schmidt EE, Ichimura K, Reifenberger G and Collins VP. CDKN2 (p16/MTS1) gene deletion or CDK4 amplification occurs in the majority of glioblastomas. Cancer Res 54 : 6321-6324, 1994
8. Simon M, Köster G, Menon AG and Schramm J: Functional evidence for a role of combined CDKN2A[p16/p14(arf))]/ CDKN2B (p15) gene inactivation in malignant gliomas. Acta Neuropathol 98: 444-452, 1999.

9. Rasheed A, Herndon JE, Stenzel TT, et al: Molecular markers of prognosis in astrocytic tumors. Cancer 94: 2688-2697, 2002.

10. Gil J and Peters G: Regulation of the INK4b-ARF-INK4a tumour suppressor locus: all for one or one for all. Nat Rev Mol Cell Biol 7: 667-677, 2006.

11. He J, Olson JJ and James CD: Lack of $\mathrm{p} 16^{\mathrm{INK} 4}$ or retinoblastoma protein $(\mathrm{pRb})$, or amplification-associated overexpression of cdk4 is observed in distinct subsets of malignant glial tumors and cell lines. Cancer Res 55: 4833-4836, 1995.

12. Ichimura K, Schmidt EE, Goike HM and Collins VP: Human glioblastomas with no alterations of the CDKN2A (p16 $6^{\mathrm{INK} 4 \mathrm{~A}}$, MTS1) and CDK4 genes have frequent mutations of the retinoblastoma gene. Oncogene 13: 1065-1072, 1996.

13. Ichimura K, Bolin MB, Goike HM, Schmidt EE, Moshref A and Collins VP: Deregulation of the p14ARF/MDM2/p53 pathway is a prerequisite for human astrocytic gliomas with G1-S transition control gene abnormalities. Cancer Res 60: 417-424, 2000.

14. Fulci G, Labuhn M, Maier D, et al: p53 gene mutation and ink4a-arf deletion appear to be two mutually exclusive events in human glioblastoma. Oncogene 19: 3816-3822, 2000.

15. Kamiryo T, Tada K, Shiraishi S, et al: Analysis of homozygous deletion of the p16 gene and correlation with survival in patients with glioblastoma multiforme. J Neurosurg 96: 815-822, 2002.

16. Wemmert S, Ketter R, Rahnenführer J, et al: Patients with highgrade gliomas harboring deletions of chromosomes $9 p$ and $10 q$ benefit from temozolomide treatment. Neoplasia 7: 883-893, 2005.

17. Simon M, Voss D, Park-Simon TW, Mahlberg R and Köster G: Role of p16 and p14 ${ }^{\mathrm{ARF}}$ in radio-and chemosensitivity of malignant gliomas. Oncol Rep 16: 127-132, 2006.

18. Herman JG, Graff JR, Myöhänen S, Nelkin BD and Baylin SB: Methylation-specific PCR: a novel PCR assay for methylation status of CpG islands. Proc Natl Acad Sci USA 93: 9821-9826, 1996.

19. Herman JG, Jen J, Merlo A and Baylin SB: Hypermethylationassociated inactivation indicates a tumor suppressor role for p15 ${ }^{\mathrm{INK} 4 \mathrm{~B} 1}$. Cancer Res 56: 722-727, 1996.

20. Esteller M, Corn PG, Baylin SB and Herman JG: A gene hypermethylation profile of human cancer. Cancer Res 61: 3225-3229, 2001 .

21. Uhlmann K, Rohde K, Zeller C, et al: Distinct methylation profiles of glioma subtypes. Int J Cancer 106: 52-59, 2003.

22. Uchida T, Kinoshita T, Nagai H, Nakahara Y, Saito H, Hotta T and Murate T: Hypermethylation of the p15 $15^{\text {INK4B }}$ gene in myelodysplastic syndromes. Blood 90: 1403-1409, 1997.

23. Kudoh K, Ichikawa $Y$, Yoshida S, et al: Inactivation of p16/CDKN2 and p15/MTS2 is associated with prognosis and response to chemotherapy in ovarian cancer. Int J Cancer 99: 579-582, 2002

24. Lee M, Sup Han W, Kyoung Kim O, Hee Sung S, Sun Cho M, Lee SN and Koo H: Prognostic value of p16 $6^{\mathrm{NK}} 4 \mathrm{a}$ and $\mathrm{p} 14^{\mathrm{ARF}}$ gene hypermethylation in human colon cancer. Pathol Res Pract 202: 415-424, 2006.

25. Paz MF, Yaya-Tur R, Rojas-Marcos I, et al: CpG island hypermethylation of the DNA repair enzyme methyltransferase predicts response to temozolomide in primary gliomas. Clin Cancer Res 10: 4933-4938, 2004.

26. Stupp R, Mason WP, van den Bent MJ, et al: European Organisation for Research and Treatment of Cancer Brain Tumor and Radiotherapy Groups; National Cancer Institute of Canada Clinical Trials Group. Radiotherapy plus concomitant and adjuvant temozolomide for glioblastoma. N Engl J Med 352: 987-996, 2005.

27. Hegi ME, Diserens AC, Gorlia T, et al: MGMT gene silencing and benefit from temozolomide in glioblastoma. N Engl J Med 352: 997-1003, 2005.

28. Watanabe T, Katayama Y, Komine C, Yoshino A, Ogino A, Ohta $\mathrm{T}$ and Fukushima T: $\mathrm{O}^{6}$-methylguanine-DNA methyltransferase methylation and TP53 mutation in malignant astrocytomas and their relationships with clinical course. Int J Cancer 113: 581-587, 2005.

29. Blanc JL, Wager M, Guilhot J, et al: Correlation of clinical features and methylation status of MGMT gene promoter in glioblastomas. J Neurooncol 68: 275-283, 2004. 
30. Crinière E, Kaloshi G, Laigle-Donadey F, et al: MGMT prognostic impact on glioblastoma is dependent on therapeutic modalities. J Neurooncol 83: 173-179, 2007.

31. Sato F, Harpaz N, Shibata D, et al: Hypermethylation of the $\mathrm{p} 14(\mathrm{ARF})$ gene in ulcerative colitis-associated colorectal carcinogenesis. Cancer Res 62: 1148-1151, 2002.

32. Hegi M, Liu L, Herman JG, et al: Correlation of $\mathrm{O}^{6}$-methylguanin methyltransferase (MGMT) promotor methylation with clinical outcomes in glioblastoma and clinical strategies to modulate MGMT activity. J Clin Oncol 26: 4189-4199, 2008.

33. Loeper S, Romeike BF, Heckmann N, et al: Frequent mitotic errors in tumor cells of genetically micro-heterogeneous glioblastomas. Cytogenet Cell Genet 94: 1-8, 2001

34. Jung V, Romeike BF, Henn W, Feiden W, Moringlane JR, Zang KD and Urbschat S: Evidence of focal genetic microheterogeneity in glioblastoma multiforme by area-specific CGH on microdissected tumor cells. J Neuropathol Exp Neurol 58 993-999, 1999.
35. Komata T, Kanzawa T, Takeuchi H, Germano IM, Schreiber M, Kondo Y and Kondo S: Antitumor effect of cyclin-dependent kinase inhibitors [p16(INK4A), p18(INK4C), p19(INK4D)]. p21 [WAF1(CIP1) and p27 (KIP1)] on malignant glioma cells. Br J Cancer 88: 1277-1280, 2003.

36. Inoue R, Moghaddam KA, Ranasinghe M, Saeki Y, Chiocca EA and Wade-Martins R: Infectious delivery of the $132 \mathrm{~kb}$ CDKN2A/ CDKN2B genomic DNA region results in correctly spiced gene expression and growth suppression in glioma cells. Gene Ther 11: 1195-1204, 2004

37. Strauss BE, Fontes RB, Lotfi CF, Skorupa A, Bartol I, Cipolla-Neot J and Costanzi-Strauss E: Retroviral transfer of the p16 ${ }^{\mathrm{INK} 4 \mathrm{a}} \mathrm{cDNA}$ inhibits C6 glioma formation in Wistar rats. Cancer Cell Int 2: 1-9, 2002.

38. Watanabe T, Katayama Y, Yoshino A, et al: Aberrant hypermethylation of p14 ${ }^{\mathrm{ARF}}$ and $\mathrm{O}^{6}$-methylguanine-DNA methyltransferase genes in astrocytoma progression. Brain Pathol 17: 5-10, 2007. 